\title{
Riding a roller coaster: narrative typologies of patients with neuroendocrine tumors
}

\author{
This article was published in the following Dove Press journal: \\ Journal of Multidisciplinary Healthcare \\ 15 December 2015 \\ Number of times this article has been viewed
}

\section{Alessia Miconi' \\ Daniele De Nuzzo' \\ Solfrid Vatne ${ }^{2}$ \\ Paola Pierantognetti'}

'Faculty of Medicine and Psychology, Sapienza Università di Roma, Rome, Italy; ${ }^{2}$ Molde University College, Molde, Norway
Correspondence: Solfrid Vatne Molde University College, PO Box 2110 , NO-6402 Molde, Norway

Tel +47 905I 5649

Email solfrid.vatne@himolde.no
Background and objective: Illness stories have attracted growing attention in health care research in the context of learning from looking at the world through the patients' eyes. No narrative studies were found about the patients with neuroendocrine tumors (NETs); a rare illness including tumors usually starting in hormone-producing cells. The aim of this article was to develop an extended understanding of these patients' experiences and struggles, as well as their solutions to a common problem.

Methods: The data source was 21 letters written by the patients with NETs treated at an ambulatory treatment center at a large urban hospital in Italy. The letters were analyzed using the Arthur Frank's narrative method. We paid particular attention to statements of self-experience, which is crucial to get the character of the story.

Results: We identified four different typologies: "Not illness stories", "Living in imbalance", "Living a new life in balance", and "Living a normal life". The main characteristics of these four groups could be linked to Frank's typologies. However, the patients with this periodically changing disease were continuously in the process of attaining balance in life, and they might move between these various typologies.

Conclusion: The NETs are incurable illnesses that challenged the peoples to attaining a new balance in life. We will highlight stories focusing on the patients' imbalance and chaos because they illuminated the patients' concrete suffering, which might provide clinicians with specific information about the patients' emotional, physical, and spiritual state. Through learning from the stories of the patients attaining new balance, it seems possible to move forward to acceptance and to develop a model for a new way of living. However, we are skeptical about labeling these stories as a model for clinical practice because they might contribute to individualistic and heroic prescriptions for life that are impossible for others to achieve.

Keywords: living in imbalance, coping and adaption, health care, life-threatening illness, neuroendocrine tumors, narrative inquiry

\section{Introduction}

The background for this research project is letters presented in a book in Italian language, ${ }^{1}$ from patients diagnosed with neuroendocrine tumors (NETs), treated at an ambulatory treatment center at a large urban hospital in Italy. The NETs is an umbrella term for tumors that arise from hormone-producing tissue. These NETs secrete hormones in an unregulated manner causing physical symptoms in unpredictable times. The organs most frequently affected are the gastrointestinal and bronchopulmonary tract. The patients' specific symptoms vary related to disease-pathophysiologies and individual characteristics. The major symptoms of NETs include fatigue, flushing, diarrhea, food intolerance, restlessness, dyspnea, fluctuations in mood, and pain. 
The symptoms may appear late in the course of the disease. Further, in most cases, the patients receive a definitive diagnosis after the tumor has metastasized. Treatment options include surgery and palliative care including biological agents, which frequently cause side effects that may be similar to the symptoms of NETs. ${ }^{2}$ Despite in most cases there is no cure, the majority of the patients live many years with more or less problems with symptoms and side effects. The NETs are a rare disease with an increasing incidence. Thus, NETs represent a challenge both for the patients and for clinical staff.

Because of the scarcity in information about NET, the aim of the book was to share experiences among the patients and inform them and their relatives about how it is to live with this rare illness. This book project was grounded in narrative medicine, which aims to build empathy and understanding between the clinician and the patient, and form communities that can combat the isolation following serious illnesses. ${ }^{3}$ We found that these letters gave rich and vivid descriptions of the patients' struggles in living with these diseases, and we were inspired to explore this material in greater depth through a narrative analysis. Studying clinical narratives might strengthen the ability to identify the perspective of the patients what they are struggling with, and what they experience as helpful in their new life with illness.

In our search for narrative studies involving the patients with NETs, we found neither narrative research nor qualitative studies. Some quantitative studies focused on NETs patients' quality of life (QOL). Beaumont et $\mathrm{al}^{4}$ and Haugland et al, ${ }^{5}$ showed that patients with NETs had an average QOL score that were significantly lower compared to the general population. However, Pezzilli et al, in a study exploring QOL in the patients with pancreatic NETs, found no significant differences in QOL between the patients with and without NETs. ${ }^{6}$ Further, the patients with progressive development of NETs had earlier average scores on general health status. ${ }^{7}$ From the perspective of the patients with NETs, health status seems good, but there is a lack of in-depth research on the patients' own narrations of the influence of NETs both personally and in their way of living.

\section{Narrative research and illness typologies}

Narrative research has become a widely used approach in health care research especially cancer patients' storytelling. ${ }^{8,9}$ Narrative analysis focuses on story in studies in which the purpose is to determine how individuals make sense of events in their life. It refers to family methods of interpreting texts, but the forms of narrative research are many, for example, in chronological and nonchronological stories. ${ }^{10,11}$ Illness narratives differ from other stories in that they have an altered temporality, where the future of those tellings is something uncertain and non-existing. ${ }^{12}$ Collective stories, where the researcher reflects the thoughts and paths of a group of patients, with similar problems and patterns of experiences are an important approach. ${ }^{13}$ Frank presents three different collective forms that illness narratives can take: the restitution narrative, the chaos narrative, and the quest narrative. ${ }^{13}$ In this study on exploring stories of NET patients' lives, we found Frank's narrative typologies compelling to our approach and understanding. We briefly present the three typologies next.

The main characteristic of restitution narratives is that someone gets sick and is treated with some remedies, with some versions of a person being is restored. ${ }^{13}$ The metaphors often used are "I am as good as new" or "I have taken my medicine and returned to the same life, without undergoing any changes, either personal or in my way of living". The patients receive treatment, and it is seen as their duty to get better. The sick person is a patient who almost has a passive character, or who relies on the expertise of the doctors, an approach that reflects the Parsons' idea about the sick role in the Western culture.

In the chaos narratives, the main characteristic is that the patients experiences that life never gets better, living a life of overwhelming suffering, or encompassing their suffering in words of silence. The patients are therefore stuck within an immovable and complex situation with obstacles of untreatable medical problems, which block movement toward any kind of meaningful response. The patients have no acceptance of their destiny; they feel out of control, because they lack a sense of the future, and have failed to see their own future life. They have given up struggling, and because of the patients' internal chaos, their stories have no structure.

Quest narratives are characterized by movements in a direction the people living with the illness experience as forward. Illness is not a good thing, but they are active characters, who have found some meaning in their illness. They have accepted their destiny, and undergone a personal change; they have gained insight into alternative ways to suffer and live. Frank presents three forms of quest narratives: 1) memoirs: the patients present events without any flourishing descriptions, insight or alternative ways of suffering; 2) manifestos: illness has been a motivator for social action and change, and the truth that has been learned is prophetic; and 3) automythology: illness is expanded to reveal fate or destiny. ${ }^{13}$ 
Many narrative research studies have used Frank's narrative theory, but we found only two narrative studies building on Frank's typology. In a study of 12 patients with breast cancer, Thomas-MacLean discovered that the restitution narrative appeared to be the most desired, because it reflected the desire to return to "normal" life. Chaos narratives occurred most often when participants spoke of bodily difficulties. Only four stories were partially framed as quest narratives. Further, as Frank shows, components of different narrative types can occur in a specific typology. ${ }^{14}$ Bally et al, who interviewed 16 parents of children in cancer treatment, discovered all three of Frank's narrative types, but there were transitions between the types. Some parents had not come to a quest narrative, or were interrupted by restitution or chaos. ${ }^{15}$

Frank's typology offers a tool for mapping stories, so that those patients' within the stories better can understand themselves, and those outside can perceive forms and regularities that open for new understanding.

\section{Methods}

In this project, the stories represented the non chronological form or plot, described as small tales, which combine into a story, characterized with a central character that encounters a problem, and a configuration that elicits an emotional response in the listener. ${ }^{11}$ It is based on the hermeneutic narrative perspective of Ricoeur, and the narrative typology described by Frank who was inspired by Ricoeur's theory of narrative identity. ${ }^{16-18}$ The narrative method works with detailed stories, most often interviews, but may also involve written stories from the patients. ${ }^{19}$ The research question asked is: What narrative typologies emerge from the NET patients' illness letters?

\section{Study subjects and data collection}

The participants in the book were invited to write as if writing to a friend with a personal presentation of themselves and their experiences of their illness so that the stories would include relevant information. In addition, they were asked some structured questions about pathology, treatment, their understanding of the disease, how they lived with the disease, what helped them, how the illness changed their life, and how they saw their future. The patients were free to use email or hand write a traditional letter. The inclusion criteria were that the patients 1) had NETs and 2) were able to write in Italian, including regional dialects. Over a 6-month period in 2013, 35 patients were recruited at the specific treatment center. We received 21 letters. The participants gave their written consent and permission for publication of the letters and to participate in the research project, and they were ensured confidentiality of their personal details in the publishing of these results. We confirm that all the research meets the ethical guidelines and has been submitted to ethics committee, including adherence to the legal requirements of the study country.

\section{Data analysis}

We analyzed the data in six steps. Because of the researchers' need for a common language, the first step became translation of all the letters from dialect into Italian and then into English. This became a back-and-forth translation in which all the authors participated; with three Italian researchers as native translators, and the fourth fluent in English. We spent time considering the meaning of various phrases and metaphors in the text, and discussed those passages in depth to reach a common understanding. We found that this process led to deeper revealing of the individual meaning in terms of a contextual understanding.

According to Riessman, it is not a specific standard procedure for analyzing narrative data. Like other types of qualitative research, it depends on the methodological framework. Thematic and structural analysis are recommended and used in this project. ${ }^{10}$ In the second step, we did a thematic analysis, with an open reading of the individual letters several times to reveal the meaning units, based on how the meaning in the individual story affected us. This process was based on Frank's descriptions of that one problem with categorization of narrative is the cutting up of an individual story, where the uniqueness of the storyteller's individual voice disappears. The story should therefore be analyzed as a whole. ${ }^{18}$ We found Frank's further descriptions of the research method not very clear, but he presents some main characteristics. He maintains that narratives, in contrast to stories, are templates, which are the fundamental narrative resources that allow for a sort of mapping and naming of collective story typologies. An important approach in disclosing the wholeness of the meaning is that the researcher asks how the stories affect the storyteller.

In addition, Frank pays particular attention to statements of self-experiences, which is crucial to get the character of the story, described as the essence of living with NETs. He also highlights that getting the essence of the storyteller's character is important. ${ }^{18}$ By focusing on such characteristics, the typologies can be developed by naming clusters of narratives, for example, narratives of the typical patient's solutions to a common problem. We therefore in the third step paid particular attention to statements of self-experiences and the char- 
acter of the story and the storyteller (see examples of Step 3 in Table 1). All these themes were intertwined in a complex way and they became a part of the naming of the typologies in step four, where we labeled each patient's typology. Some phrases used by the patient became important. ${ }^{18}$ Further, Frank presents that by arranging the clusters along a continuum, by generating a matrix, the readers can perceive the form and regularities of illness stories. Therefore, we in step five developed a matrix, where the themes from each story also were sorted in typologies (like the examples given in Table 1).

Then we in step six, on the background of the matrix, performed a cross-case analysis, and identified the structures across the individual narration to explore differences in the patients' narrated experiences to identify the collective typologies. ${ }^{18}$ All authors worked together to re-sort and name the different typologies as presented in (Figure 1). In this process, we still stayed close to our data, and related our typologies to Frank's typology first after developing our main typologies.

\section{Results}

The patients' stories reflected both sociodemographic and medical characteristics (Table 2).

A total of 13 women and eight men, participated in this study, aged between 36 and 74 years, with NETs mainly in the gastrointestinal tract (11) and pancreas (9), and metastasis (17) mainly to the liver (12), lungs (3), and liver and bones (2); three had other places. Time since diagnosis ranged from 2 to 16 years. The patients had been treated with surgery (11) and/or various kinds of biological agents (19). Most of the patients suffered from the sequel of the NETs such as loss of energy, flushing, having a light-headedness, diarrhea, nausea, cold sweat, hyperglycemia, ulcers, pain, frequent infections, or intolerances of the medication (similar to symptoms of the illness itself).

\section{Narrative typologies developed from NET patients' illness letters - related to Frank's typologies}

Most of the patients' letters started with a description of the patients' reaction to receiving the diagnosis. They described this early phase as a state of chaos, confusion, total collapse of their world, and a tunnel of darkness where they feared that the worst could happen to them. How fast they passed through this first chaotic treatment phase of great psychological distress varied, as did the struggle and fight against symptoms and side effects. We use the typology presented in Figure 1 as the structure for the further presentation of the results.

\section{Not illness stories}

We characterized the stories of three patients, all men, as "not illness stories" because their narratives merely stated facts of medical information with very few characteristics of their illness like their symptoms, personal descriptions of changes in life, their way of living, and how they personally handled their illness. The patients who reflected the "not illness stories" had all been treated with surgery. They had lived with their diagnosis in 3-5 years, and two of them had liver metastasis. All three patients lived without closeness to a partner or family. A quotation from one patient with bone and liver metastasis represents a common voice of this group of patients:

I definitely have accepted my illness, because I feel in good hands and my character has not changed to be an illness tragedy (male, 72 years).

After surgery, they returned to work as soon as possible although, they had a variety of severe symptoms. These men took their medication and had little time to think of their disease. Nevertheless, all three felt insecure about what would happen to them in the future. The typology can be summed up in the phrase "I am sick, but I feel good, I feel fit, and I have the same desire to do things", which matches the character of a restitution story.

\section{Living in imbalance}

The voices of all the ten patients (nine women) in this group pointed to a great imbalance the disease created in their lives, and that they were trying to attain balance in life, because they could not control the cancer, the cancer could win. The majority of the patients treated with biological agents, which caused serious side effects, were represented in this group. Their stories described a life with great pain and psychological stress, which had also influenced their daily life in general such as a lack of energy and confusion. Some vivid remarks from several patients were:

I live in a tunnel of confusion.

The worst is that my illness has affected my consciousness.

My life is like riding on a roller coaster - there are ups and downs, but mostly bad days.

They described that every day they were pulling themselves together - to go on with their life. If they tried to do 


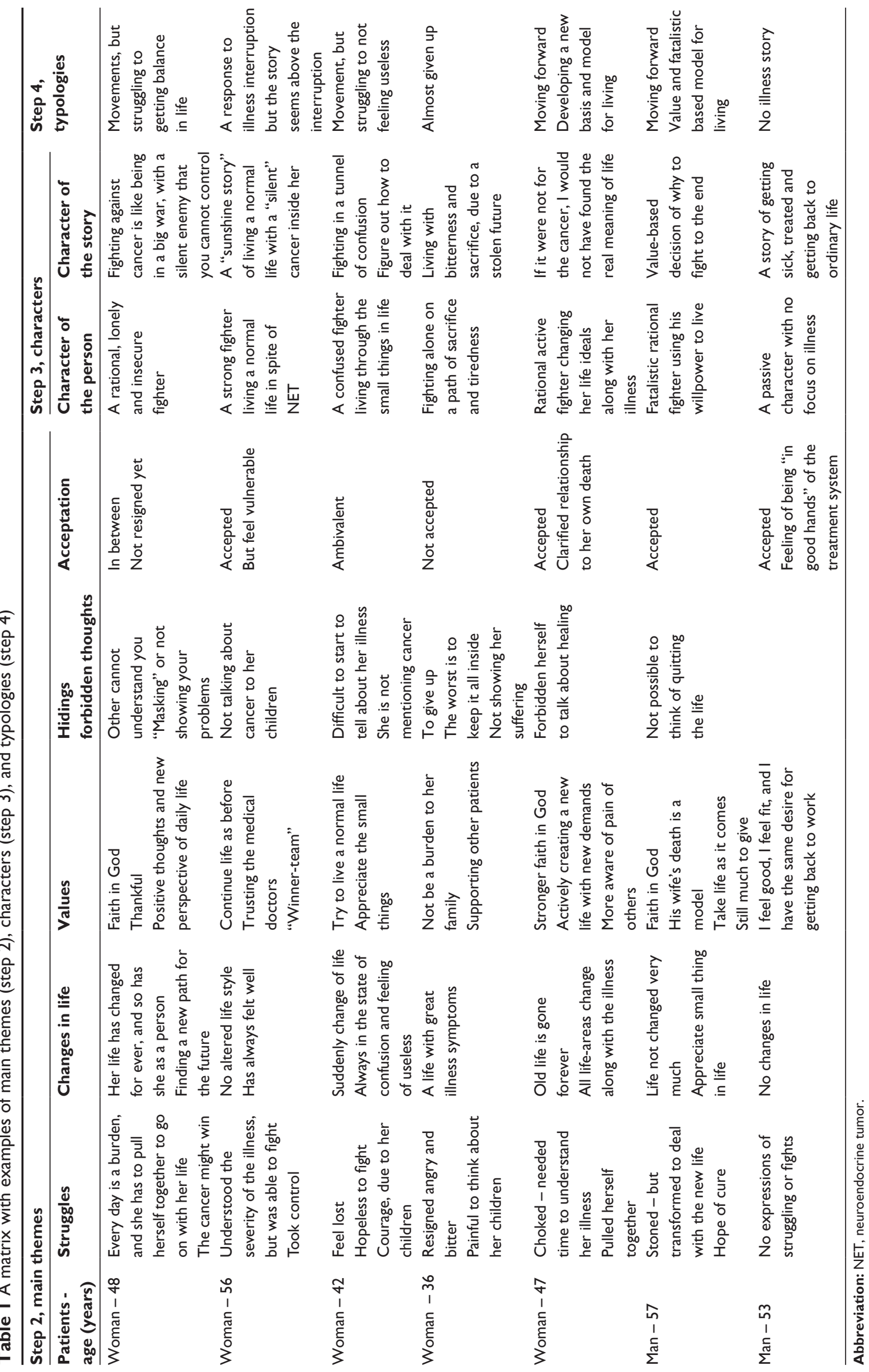




\begin{tabular}{|c|c|c|c|}
\hline $\begin{array}{l}\text { Not illness } \\
\text { stories } \\
\text { with no } \\
\text { descriptions of } \\
\text { the impact of the } \\
\text { illness on their } \\
\text { life } \\
\text { "I am sick, but I } \\
\text { feel good, I feel } \\
\text { fit, and I have the } \\
\text { same desire to do } \\
\text { things" }\end{array}$ & $\begin{array}{l}\text { Living in imbalance } \\
\text { with a great burden } \\
\text { of side effects } \\
\text { a. Fighting a } \\
\text { difficult war } \\
\text { b. Walking a } \\
\text { path of } \\
\text { sacrifice and } \\
\text { tiredness- } \\
\text { giving up? }\end{array}$ & $\begin{array}{l}\text { Living a new life } \\
\text { in balance } \\
\text { with a positive } \\
\text { model for fighting } \\
\\
\text { a. Positive } \\
\text { realistic } \\
\text { fighters } \\
\text { b. Fatalistic } \\
\text { rational } \\
\text { fighters }\end{array}$ & $\begin{array}{l}\text { Living a normal life } \\
\text { with the illness silent } \\
\text { inside } \\
\text { "The lucky winners" }\end{array}$ \\
\hline
\end{tabular}

Figure I Overview of main typologies developed from the patients' letters.

ordinary things, the result might be a feeling of frailty or uselessness:

I was often tired, lost my appetite, and could not move normally. Even small things were a great burden. A situation like this "threw me down in the dumps" because I felt useless. I could not even take care of my son, ordinary things. It was devastating to my mind (female, 42 years).

The same patient said that through help from a psychologist she was able to get answers she could not find either by herself or through help from her family.

Nevertheless, some patients in spite of imbalance wrote, that they had developed a new value for their life such as spending their given time close to others and doing things they liked. Others expressed that they now were giving the

Table 2 Participants characteristics, $\mathrm{N}=2$ I

\begin{tabular}{ll}
\hline Sex of the participants & 13 \\
Female & 8 \\
Male & $36-74$ \\
Age (years) & \\
Primary cancer site & 11 \\
Gastro-intestinal tract & 9 \\
Pancreas & 1 \\
Lungs & 3 \\
Other & 17 \\
Metastasis (several places) & 12 \\
Liver & 3 \\
Lung & 2 \\
Skeleton & 3 \\
Other & 3 \\
Years since diagnosis & $2-16$ \\
Treatments & \\
Surgery & 11 \\
Radiotherapy & 8 \\
Somatostatin Analogs & 10 \\
Everolimus & 9 \\
Chemotherapy & 3 \\
Chemoembolization & 3 \\
Interferon & 2 \\
\hline
\end{tabular}

things in life the right weight. Several wrote that it was hard to reach an acceptance and to appreciate that their lives had become different from their former lives as well as that they had a diminished future.

For some patients, their experience of support from family and friend was the most important in giving them the "strength to fight" and "courage to go on". Others said they were hiding their suffering from those closest to them, because they did not want to burden them or because they were feeling shame, for example:

I always have a big smile on my face.

I am dressing funny and am using colored glasses - not

showing my problems.

One of the tellers said that she, in-fact would love to share experiences and feelings with people who have the same problems, because that would allow her to feel less alone.

We identified eight patients in this group of "fighting a difficult war". They described their imbalance was related to severe side effects. Most of them were naming their cancer with negative concepts, for example:

I have a witch in my body I am running together with.

My illness is always present like a ghost, I was hit by

an evil disaster.

This ugly beast in my body.

These quotations showed that they differ from the others, experienced the cancer as an intrusive active alien in their body, which had not yet become a part of them, and with whom they have to fight against. It is interesting that none of these patients wrote that they accepted the disease, but some that they were ambivalent. Only one talked about the cancer as both a positive and negative actor that gave her early warnings, and that the cancer gave the things in her life a right weight. She expressed, that for her to win the war, she 
needed to negotiate with this negative actor in her life, but she did not know who was going to win.

The patients described various ways of fighting a difficult war against the cancer. One 75-year-old female patient with severe pulmonary metastasis illustrated her situation of bearing her burden of her illness in hopes for a better treatment for the next generation. Another wrote that she had earlier won the war against breast cancer, and promised herself that she could fight against this too. We find that both stories reflect a distinctive model for their fight.

We identified two of the ten patients "walking a path of sacrifice and tiredness", who were close to giving up. Both gave voice to the experience that their struggling was a sacrifice, and that they were filled with bitterness because of a "stolen future". They had not accepted their destiny. The cancer had changed their life forever and that was too great a burden to endure. Both had years of symptoms and tests before they were diagnosed, and it was hard for them to accept all the inconvenience of side effects.

In all these years, the hardest thing to deal with was not to know what I had. Those who do not know me very well, they think I am good. However, this I will not recommend. You have to talk about it; do not keep it inside, which is the worst thing you can do. I see my future without certainty, always dependent on drugs and tests. Sometimes I would like to have a break for a year (female, 36 years).

This woman's understanding was that the hardest burden is to keep it all inside and being alone with her suffering. In addition, these two patients saw no substantial improvement in the near future. They wanted their former life back.

All the patients in the "living in imbalance" typology match the main characteristic of chaos narratives: Life never gets better and they live a life with overwhelming suffering. What is special with NET-illness, are that it is no cure, and the patients have to live with severe side effects, and worries about their future probably for many years. Nevertheless, there are major variations in relation to Frank's characteristics. Only the two patients identified as "walking a path of sacrifice and tiredness" were almost giving up, stuck within an immovable complex situation of untreatable suffering, and having no desires for their life. The other patients were still struggling.

\section{Living a new life in balance}

All six patients in this group wrote that their former life had gone forever, which was "a life where they were strong". One strong example is:
I went into a total state of confusion, but "pulled myself together".

However, they tried actively to create a new life. Almost all had been treated with chemotherapy (four of five). The majority of the patients' had stopped working because of problems related to illness and high age. They described life as challenging, but the burden seemed less than that of the patients in imbalance. Like "the patients in imbalance", they talked about a shrunken horizon and day-to-day living. The most striking difference was the way they expressed acceptance of the illness; the illness had become a part of them. They were facing their destiny and not fighting against it. In addition, they had attained a clarified relationship to their own death and had found a new value-based model, for living, but the model was different.

The three patients in the group that we labeled "positive realistic fighters" were all women. Their written voices were emotional and value charged with vivid and detailed descriptions. They wrote that the illness had transformed all areas of their life: work, state of mind, interests in life, and their body and as a person. They were looking at the world with different eyes described as that they were more thankful, and that they more fully admired what they called "the small things in life", and the beauty of nature. For example, participants stated they had become a better person, more aware of and open to other people's feelings, that they better understood other people, and that they did not take anything for granted anymore. One patient wrote:

I consider that one of my greatest opportunities for renewal is if it [the cancer] had not come and told me to change, to make better use of the time that remains in my life, it would have been a real shame (female, 47 years).

Moreover, achieving a new balance had required a great deal of energy. One patient expressed that she had forbidden herself to think of healing. Another had made her decision to use her life in an organization for helping people with NETs, which also helped her to escape from her loneliness. All three patients wrote that after the disease they had strengthened their spiritual values. In particular, their new moral values allowed them to be in balance with the disease and the treatment problems. In this group, the catholic religious faith, become a model for living during the progression of the disease:

I faced it all with the serenity I have, due to my faith in Jesus, knowing that $\mathrm{He}$ is always with me in my tests, in any treatment, when I am feeling bad. He is the only One 
that understands me because He has suffered pain before me, and $\mathrm{He}$ won (female, 43).

Together with their faith in God, their family and the medical system have been sources of strength in the fighting process.

The voices from the three men that we labeled "fatalistic rational fighter" were also vivid and emotional. When writing about emotions, however, they expressed themselves in a more matter-of-fact and rational way. The most striking common characteristic was the fatalistic view they expressed in the letters:

I approached the situation in a fatalistic manner, and with a certain degree of unconsciousness. Life has taught me that it is useless in certain cases to get angry or bang your head against the wall. I remained quiet and a little bit resigned. I faced my destiny doing everything there was to do, and relying on those who have giving me confidence (male, 63 years).

They all wrote that they had gained their strength back after the surgery by using their own willpower, for example:

I tried to get back my physical strength by doing exercise.

I went hunting two weeks after surgery.

I went back to work as soon as possible.

Another common feature was that their anticipation of life had changed such as being more sensitive to others, having more awareness of what was important in their new life, and that they were not asking too much for themselves anymore. Some expressed that they had got a distance to what life could give them of new projects. One wrote:

If you ask me about how I see the future, I am in trouble, because my horizon has shrunk, I feel a little bit foggy. You can no longer navigate on autopilot. You navigate by sight (male, 60 years old).

This patient is saying that his earlier life was a kind of carefree life, but now he has to make an effort to decide step by step what to give priority. Although these patients wrote that their lives had not changed much, they all talked about their struggles with side effects and facing their own death, which had made them stronger. While they had not sacrificed very much, they were still living with some wounds. One wrote that he could not take any more now, another that he had a terrible feeling of loneliness in spite of support from his family.
All the patients in the "living a new life in balance" group match the characteristics of quest narratives. They have walked through the most difficult path of "the journey" and have found some meaning in the illness and a new meaning in life. Although they are coping, they are still in doubt about what might happen to them in the future. When the three women described their gratitude for the way that the illness had changed their life and their faith in God, they spoke in a prophetic voice. The men seemed more to trust their own willpower. All talked about the renewal of values that had made them a better person for other people, which is similar to what Frank named manifestos. All these patients were also strong advocates for the characteristic of automythology, in the way they talked about their fate and acceptance of their destiny.

\section{Living a normal life}

Two patients, a woman and a man, wrote in a personal style, the woman also emotionally, that in spite of liver metastasis they were living a normal life. Their illness had been discovered accidentally, and they had very few symptoms. Both have had surgery. The cancer was still living silently inside them, but they felt good:

Overall, I can say that my life has not undergone changes worthy of concern; I have lived with the disease quietly and peacefully. My family hardly speaks about my illness, because my presence is characterized by behaviors of a healthy person - and not a sick one (male, 74 years).

Their disease was under control through a team of medical staff, who, together with the patients, seemed to be the "winners". Nevertheless, we also found insecurity in their voices; the disease was "blocked", but not cured and had to be monitored constantly. They expressed the hope that their normal condition would continue. One wrote that the disease had developed negatively. The patients "living a normal life" match the main characteristics of the restitution narrative.

\section{Discussion}

The findings from this research illustrate great variation in how the patients with NETs experience the burden of their illness, the way they manage to live with it, and their QOL. This variation cannot be revealed by the use of standard QOL instruments, which showed earlier average scores for the patients with NETs. ${ }^{3,4,6}$ Moreover, our findings largely agree with narrative research findings on the cancer patients' storytelling in general; cancer patients experience a danger for their future life, some are fighting a difficult war, but for some 
it is an opportunity for personal growth, which is important to share with others. ${ }^{20,21}$ Persson and Hallberg, interviewing patients with leukemia and malignant lymphoma also identified themes similar to those found in this study: 1) believed in life, fought for it and came through stronger; 2) life went on, patients adapted and found a balance in their new life; 3) life was over, patients felt out of control and lost their belief in life. ${ }^{22}$

Consistent with findings from international research, we found that the main characteristics in Frank's three narrative typologies matched the typologies we developed from illness stories written by the patients with NETs: restitution narratives - "not illness stories" and "living a normal life"; chaos narratives - "living a life in imbalance"; quest stories "living a new life in balance". ${ }^{13,14}$ In spite of similarities in the main characteristics, our typologies differed from Frank's in some ways: "not illness stories" and "living a normal life", both matched restitution narratives, but reflected different voices. Unlike narratives from patients who described, "living a normal life", "not illness stories" contained no personal and emotional descriptions. In addition, beyond the overall positive statements about good treatment and restoration to a normal life, in both groups we discovered an undertone of insecurity and frailty, they felt well, but were insecure about having a serious illness and having to undergo medical tests regularly for the rest of their lives. For one of the patients in the "living a normal life" group, serious liver metastasis recently had been discovered. The description of themselves as "winners" can be read as a hope for full restitution, which is also welcomed by the medical system. ${ }^{14,15}$

The patients' reason for not disclosing their problems in the "not illness stories" might be that they were not facing their emotions, and/or that they found it difficult to articulate their experiences in written text. If so, their stories seemed to be more like "living in imbalance" stories and could be interpreted as hidden chaos narratives. The fact that life and death were not overtly discussed in their letters might be viewed as a coping strategy for living with a life-threatening disease. In the "living a new life in balance" utterances like "... forbidden myself to talk about healing" can also be viewed as a defense strategy against the great pain of having a threatening cancer.

We found the greatest divergence between chaos narratives and "living in imbalance." An important characteristic of chaos narratives is a lack of structure in the patients' stories, and that the patients are resigned. ${ }^{13}$ Almost all the written letters, including those in the "living in imbalance" group, were well structured. Reasons for this finding may be that:
1) written forms are usually more structured than a dialog in interviews; 2) in the invitation letter, the patients were given a structure to follow. In addition, only the two patients in the "walking a path of sacrifice and tiredness" group seemed almost to have given up. The eight patients "fighting a difficult war" were still active fighters, and some had developed a model for their fight, which is a characteristic of the quest narrative. Our interpretation is that the patients in this group might be characterized as falling between chaos and quest narratives. With more help and time, they might reach a new life in balance. A quest narrative might then be written, or some might give up. All the patients in the "living in imbalance" group were talking about great bodily difficulties and suffering, as in Thomas-MacLean's ${ }^{14}$ research, and according to Frank, ${ }^{13}$ they are the truly vulnerable persons.

The patients "living a new life in balance", presented their character, their values and their model for living in idealistic terms and are likely to be what Frank calls "heroic". ${ }^{13}$ While in their letters they placed no emphasis on the difficulties and how they had failed, they could deprecate those who had failed, such as the patients in the "living in imbalance" group. The letters also showed that the voices of the women were more prophetic than were those of the men, who had their own willpower as an ideal. When the men wrote about getting back to work as soon as possible, we might see some elements from restitution narratives. According to Frank, there are no sex differences in narrative typologies. ${ }^{18}$ Our data are not rigorous enough to for us to challenge such a statement. Nevertheless, we find it interesting that in the typology "living in imbalance", "the largest group and the patients who experienced most suffering were women". Salander and Hamberg, ${ }^{23}$ who examined narratives written by 83 patients with cancer, found that women wrote longer narratives and in a more personally and emotionally style than men's style. This result may support our suggestion that the men who wrote "not illness stories", belonged to the "living in imbalance" typology, but there are reasons to be cautious about such an explanation.

An important question to ask is how restitution and quest narratives might be disrupted when the illness progresses negatively. We agree with Thomas-MacLean that reconstruction of living, rather than restitution, might be understood as the underlying structure of cancer. ${ }^{14}$ That might be the case for the patients with NETs, where both the cancer itself and the treatment seem to have great influences on the patients' life, and that for most of them there is no cure. A negative illness change might influence a drastic shift in typology.

The patients told that they were grateful for what they learned from writing letters through the encouragement 
we gave them, which led them to start thinking through the changes in life with NET. Some persons pointed to the importance to share experiences, to get out of their loneliness. According to Ricoeur, using narrative is not merely a way of reflecting one's experiences, but is also a way of creating new experiences continuously. ${ }^{17}$ Written and verbal narratives might give new meaning and insight to earlier experiences. Retelling them is all about bringing the past into the present to form a future life.

\section{Conclusion}

The results of this study add knowledge to Frank's narrative typology of how the patients handle their cancer experiences: "not illness stories", "living in imbalance", "living a new life in balance", and "living a normal life". The way in which people experience their illness might be a critical factor for their lives as long-term patients. Returning to a life similar to the one before cancer, like a full restitution, might not be possible. Although the main characteristics in each typology that we identified can be linked to one of Frank's typologies, other characteristics match other typologies just as well. The patients seem continually to be in the process of finding ways of coping with illness.

We highlight stories focusing on the patients' imbalance and chaos because they illuminate the patients' concrete suffering, which provides clinicians with specific information about the patients' emotional, physical, and spiritual state. Listening carefully to a patient's story might be a starting point for helping them to find their own resources to attain balance. Through learning from quest stories, it seems possible to move forward to acceptance and to develop a model for a way of living with cancer. Nevertheless, we are skeptical about an uncritical use of quest narratives as a model for clinical practice because they might contribute to individualistic and heroic prescriptions for life that are impossible for others to achieve. Additional research is required to examine how these narratives can be used in supporting the patients.

\section{Study limitations}

This study is based on the patients' letters obtained for another purpose, and it is possible that the data were not as rich or in depth as data from an interview study might be. However, patients in an interview are not given the same opportunity to give structure to the information they want to present, but they may also be disturbed by the interviewer's questions. Josselson, who has used both verbal and written narratives, maintained that in oral narratives, the current sense of the self and the person's identity was much less clear than in the written narrative. ${ }^{19}$
The patients' letters might therefore give a stronger presentation of the character of the storyteller and the story, which according to Frank are important features in the development of a narrative typology. ${ }^{18}$ We see that in-depth interviews of the same patients might have added a deeper insight into the patients' struggles, for example, in the "not illness narratives", and thereby strengthened the study. Furthermore, all the patients were from the same ethnic group with similar cultural backgrounds, which might make it difficult to transfer findings to the patients with NETs in other cultures.

\section{Acknowledgment}

We gratefully thank the patients who participated in the study and so generously shared their life experience with cancer.

\section{Disclosure}

The authors report no conflicts of interest in this work.

\section{References}

1. Stori di tumori neuroendocrini: I pazienti raccontano (Patients own told stories of neuroendocrine tumors), (not published).

2. Delle Fave G, Kwekkeboom DJ, Van Cutsem E, et al. ENETS consensus guidelines for the management of patients with gastroduodenal neoplasms. Neuroendocrinology. 2012;95(2):74-87.

3. Charon R. The patient-physician relationship. Narrative medicine: a model for empathy, reflection, profession, and trust. JAMA. 2001; 286 (15):1897-1902.

4. Beaumont JL, Cella D, Phan TA, Choi S, Liu Z, Yao JC. Comparison of health-related quality of life in patients with neuroendocrine tumors with quality of life in the general US population. Pancreas. 2012;41(3): 461-466.

5. Haugland T, Veenstra M, Vatn MH, Wahl AK. Improvement in stress, general self-efficacy, and health related quality of life following patient education for patients with neuroendocrine tumors: a pilot study. Nurs Res Pract. Epub 2013 Apr 23. doi: 10.1155/2013/695820.

6. Pezzilli R, Campana D, Morselli Labate AM, Fabbri MC, Brocchi E, Tomassetti P. Patient-reported outcomes in subjects with neuroendocrine tumors of the pancreas. World J Gastroenterol. 2009;15:5067-5073.

7. Teunissen JJ, Kwekkeboom DJ, Krenning EP. Quality of life in patients with gastroenteropancreatic tumors treated with $\left[{ }^{177} \mathrm{Lu}-\mathrm{DOTA}^{0}, \mathrm{Tyr}^{3}\right]$ octreotate J Clin Oncol. 2004;22(13):2724-2729.

8. Kleineman A. The Illness Narratives: Suffering, Healing and the Human Condition. New York: Basic Books; 1998.

9. Overcash J. Narrative research: a viable methodology for clinical nursing. Nurs Forum. 2004;39(1):15-22.

10. Riessman CK. Narrative Methods for Human Sciences. Los Angeles, CA: Sage; 2008.

11. Holloway I, Wheeler S. Quality Research in Nursing and Health care. 3rd ed. Oxford: Wiley-Blackwell; 2010.

12. Creswell JW. Qualitative Inquiry Research Design. 3rd ed. London: Sage; 2013.

13. Frank AW. The Wounded Storyteller. Body, Illness, and Ethics. Chicago: The University of Chicago Press; 1995.

14. Thomas-MacLean R. Understanding breast cancer stories via Frank's narrative types. Soc Sci Med. 2004;58(9):1647-1657.

15. Bally JM, Holtslander L, Duggleby W, et al. Understanding parental experiences through their narratives of restitution, chaos, and quest. Improving care for families experiencing childhood cancer. J Fam Nurs. 2014;20(3):287-312. doi: 10.1177/1074840714532716.

16. Ricoeur P. From Text to Action. London: Continuum; 2008. 
17. Ricoeur P. Life in Quest of narrative. In: Wood D, editor. On Ricoeur: Narrative and Interpretation. London: Routledge; 1991:20-33.

18. Frank AW. Letting Stories Breathe. A Socio-narratology. Chicago: The University of Chicago Press; 2010.

19. Josselson R. Narrative research. Constructing, deconstructing and, reconstructing story. In: Wertz FJ, editor. Five Ways of Doing Qualitative Analysis. New York: Guilford Press; 2011:224-242.

20. Pelusi J, Krebs LU. Understanding cancer - understanding the stories of life and living. J Cancer Educ. 2005;20(1 Suppl):12-16. doi: 10.1207/ s15430154jce2001s_04.
21. Whitehead LC. Quest, chaos and restitution: living with chronic fatigue syndrome/myalgic encephalomyelitis. Soc Sci Med. 2006;62(9): 2236-2245.

22. Persson L, Hallberg IR. Lived experiences of survivors of leukemia or malignant lymphoma. Cancer Nurs. 2004;27(4):303-313.

23. Salander P, Hamberg K. Gender differences in patients' written narratives about being diagnosed with cancer. Psychooncology. 2005; 14(8):684-695.

\section{Publish your work in this journal}

The Journal of Multidisciplinary Healthcare is an international, peerreviewed open-access journal that aims to represent and publish research in healthcare areas delivered by practitioners of different disciplines. This includes studies and reviews conducted by multidisciplinary teams as well as research which evaluates the results or conduct of such teams or healthcare processes in general. The journal covers a wide range of areas and welcomes submissions from practitioners at all levels, from all over the world. The manuscript management system is completely online and includes a very quick and fair peer-review system. Visit http://www.dovepress.com/testimonials.php to read real quotes from published authors.

Submit your manuscript here: http://www.dovepress.com/journal-of-multidisciplinary-healthcare-journal 